\title{
THE INNERVATION OF BRACHIALIS MUSCLE BY RADIAL NERVE IN GUJARAT REGION - A HUMAN CADAVERIC STUDY
}

\section{Natwar Lal Gaur ${ }^{1}$, Jagdish S. Soni ${ }^{* 2}$, Samta Gaur ${ }^{3}$.}

${ }^{1}$ Assistant Professor, Department of Anatomy, Index Medical College Hospital \& Research Centre Indore, Madhya Pradesh, India.

${ }^{* 2}$ Associate Professor, Department of Anatomy, Medical College Baroda, Gujarat, India.

${ }^{3}$ Tutor, Department of Anatomy, Government Medical College Pali, Rajasthan, India.

\section{ABSTRACT}

Background: Though the supply to the human brachialis muscle by radial nerve has been investigated by many authors in past, but there is no consistency in these reports. The aim of the present study was to record the anatomical variations in radial nerve supply to the brachialis muscle.

Materials and Methods: The material of the study consisted of 62 superior extremities obtained from dissection laboratory of department of anatomy, Medical College Baroda (Gujarat). All these extremities belonged to adult cadavers of known sex.

Human brachialis muscle was identified with its proximal and distal attachment. The radial nerve branch innervating to brachialis was identified and parameters like presence or absence of radial nerve branch innervating to brachialis; number of branches; its length; site of emergence and its distance from lateral epicondyle and site of entry into brachialis were noted.

Result: Brachialis muscle was innervated by a branch from radial nerve in $87.09 \%$ of cases. Varying number of radial nerve branches ( 1 to 3 ) innervated the brachialis muscle. Most of these branches (91.93\%) entered the lower one third of the muscle. The average length of these muscular branches was $9.17 \mathrm{~mm}$. The average distance from the site of emergence to the lateral epicondyle of humerus was $6.54 \mathrm{~cm}$.

Conclusion: Significant variations in supply of brachialis muscle were recorded. These variations are of clinical importance for surgeons, orthopaedicians and anaesthetists.

KEY WORDS: Human Brachialis Muscle, Radial Nerve, Lateral Epicondyle of Humerus.

Corresponding Author: Dr. Jagdish S. Soni, P-13 Aviral Society, Opp.- Mangalam duplex, Sama savli road, Baroda, Gujarat, India. Pin-390024 E-Mail: ashushiti@yahoo.co.in

Access this Article online

Quick Response code

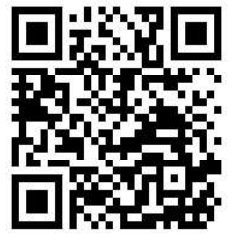

DOI: $10.16965 /$ ijar.2019.369
Journal Information

International Journal of Anatomy and Research

ICV for 2016 ISSN (E) 2321-4287 | ISSN (P) 2321-8967

90.30

https://www.ijmhr.org/ijar.htm

DOI-Prefix: https://dx.doi.org/10.16965/ijar

\section{Article Information}

Received: 19 Dec 2019

Peer Review: 19 Dec 2019

Revised: 05 Jan 2020
Accepted: 23 Jan 2020

Published (O): 05 Feb 2020

Published (P): 05 Feb 2020

\section{INTRODUCTION}

The musculocutaneous nerve ( $\mathrm{C} 5$ and 6 ) supply the motor fibers to the brachialis muscle. The radial nerve is proprioceptive (C7) to a small lateral part of the muscle. It is the only pure flexor, producing the greatest amount of flexion force [1-3] therefore brachialis is often called work-horse of the elbow joint [4].
Radial nerve pierces the lateral intermuscular septum, $5 \mathrm{~cm}$ below deltoid tuberosity, to enter the anterior compartment of arm on its lateral aspect $[5,6]$. Here, the lateral part of brachialis is most often supplied by the radial nerve [7]. Our aim of study was to find out anatomical variations in the origin \& course of radial nerve supplying to the brachialis muscle and to correlate these variations with clinical importance. 


\section{MATERIALS AND METHODS}

The material of the study consisted of 62 superior extremities obtained from dissection laboratory of department of anatomy, Medical College Baroda (Gujarat). All these extremities belonged to adult cadavers of known sex belonging to Gujarat region.

The brachialis muscle was exposed by routine dissection method [8]. The radial nerve was exposed in lower $1 / 3^{\text {rd }}$ of anterior aspect of arm (i.e., from the point where it pierces the lateral inter-muscular septum up to the point where it lies on anterior aspect of lateral epicondyle of humerus). Branch(es) of radial nerve supplying to the brachialis were exposed.

The following data were recorded for both the sides-

- The presence or absence of the muscular branches of the radial nerve to the brachialis muscle.

- The number of muscular branches of the radial nerve to the brachialis muscle

- The site of entry of the muscular branches of the radial nerve to the brachialis muscle (i.e., whether in the upper one third, middle one third or the lower one third of the muscle).

- The length of the muscular branches of the radial nerve to the brachialis muscle

- The distance of the muscular branches from their site of origin to the lateral epicondyle,

Digital Vernier calipers of $0.02 \mathrm{MM}$ accuracy was used for linear measurements. Data were tabulated and analyzed statistically.

\section{RESULTS}

In the present study the radial nerve branch to brachialis muscle was found to present in 54 upper limbs and absent in 8 limbs (Fig. 1).

The number of branches from radial nerve to brachialis muscle were found to present as under: 1 branch in 24 limbs, 2 branches in 17 limbs and 3 Branches in 13 limbs (Fig. 2).

The site of entry of the radial nerve branches into the brachialis was found in its upper $1 / 3$ in 12 limbs; in middle $1 / 3$ in 27 limbs and in lower $1 / 3$ in 57 limbs (Fig. 3).

The length of the muscular branches (from radial nerve to its entry in brachialis muscle) varied. The mean length of the first (upper branch) was $9.92 \mathrm{~mm} \pm 6.30$, second was $9.04 \mathrm{~mm}$ \pm 7.08 and the third was $8.55 \mathrm{~mm} \pm 2.80$. The average length of these muscular branches was $9.17 \mathrm{~mm}$. (Table 1).

Table 1: Number of muscular branches and their length in $\mathrm{mm}$.

\begin{tabular}{|c|c|c|c|c|}
\hline Variable & $\begin{array}{c}\text { Number of } \\
\text { limbs (N) }\end{array}$ & Range of length & Mean of length & SD \\
\hline First Branch & 54 & 2.03 to 34.24 & $9.92 \mathrm{~mm}$ & 6.3 \\
\hline Second Branch & 30 & 1.70 to 40.64 & $9.04 \mathrm{~mm}$ & 7.08 \\
\hline Third Branch & 13 & 4.0 to 13.03 & $8.55 \mathrm{~mm}$ & 2.8 \\
\hline
\end{tabular}

The distance from the site of emergence of the muscular branches to the lateral epicondyle of humerus is presented in (Table 2).

Table 2: Number of muscular branches and their distance from the site of emergence to the lateral epicondyle in $\mathrm{cm}$.

\begin{tabular}{|c|c|c|c|c|}
\hline Variable & N & Range & Mean & SD \\
\hline First Branch & 54 & 2.5 to 16.5 & $8.24 \mathrm{~cm}$ & 3.33 \\
\hline Second Branch & 30 & 3.5 to 11.9 & $6.55 \mathrm{~cm}$ & 2.35 \\
\hline Third Branch & 13 & 2.5 to 11.17 & $4.84 \mathrm{~cm}$ & 2.3 \\
\hline
\end{tabular}

Fig. 1: Showing presence or absence of radial nerve branch innervating to Brachialis muscle.

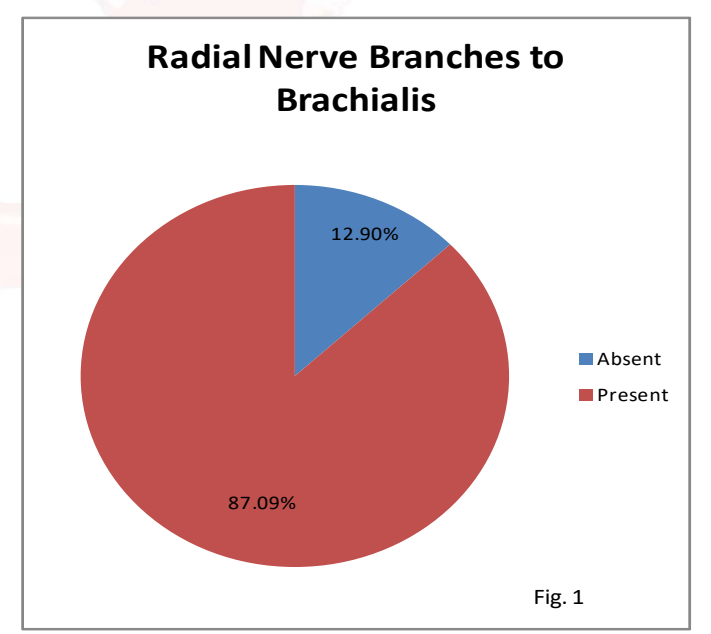

Fig. 2: Graph showing number of branches from radial nerve to brachialis muscle.

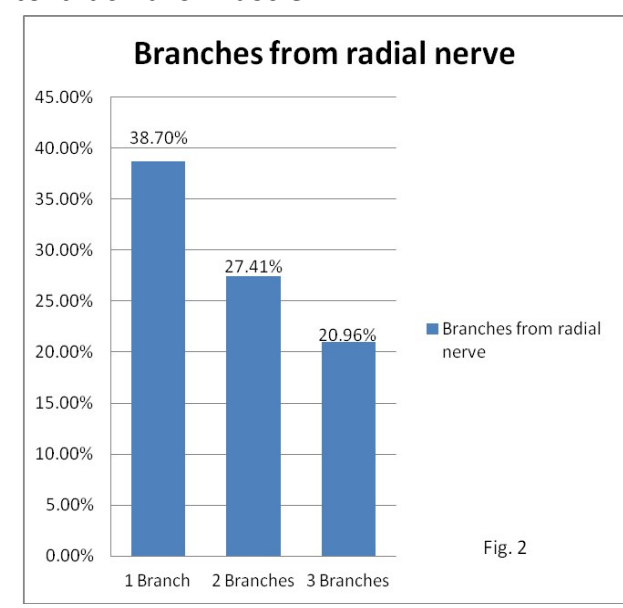


Fig. 3: Graph showing site of entry of the radial nerve branches into the Brachialis.

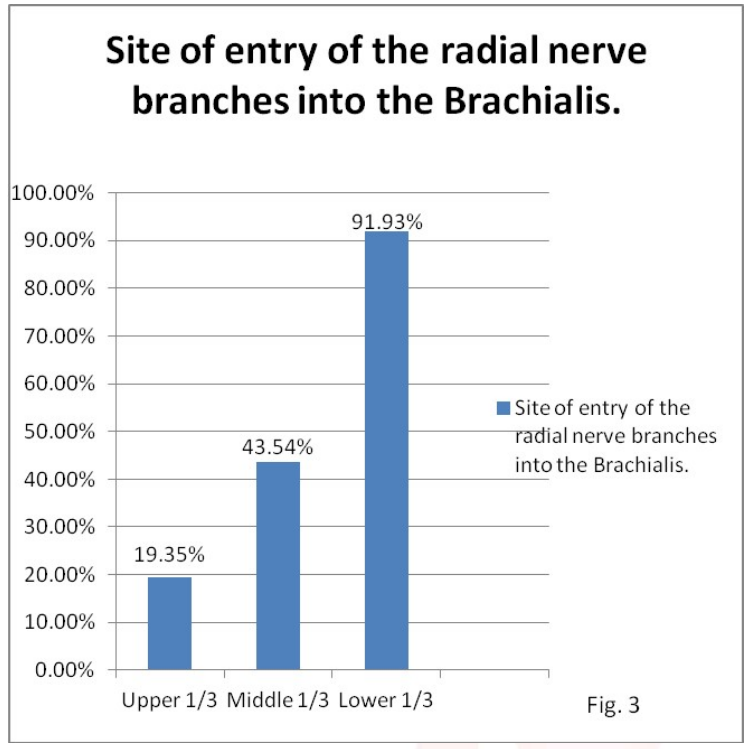

Fig. 4: Photograph showing two muscular branches from radial nerve of left limb entering lower one third of brachialis muscle.

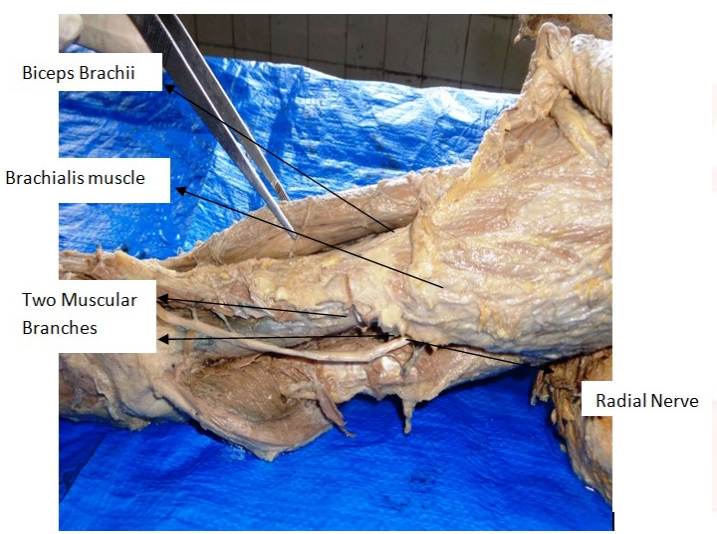

Fig. 5: Three muscular branches from radial nerve of right limb entering to brachialis muscle.

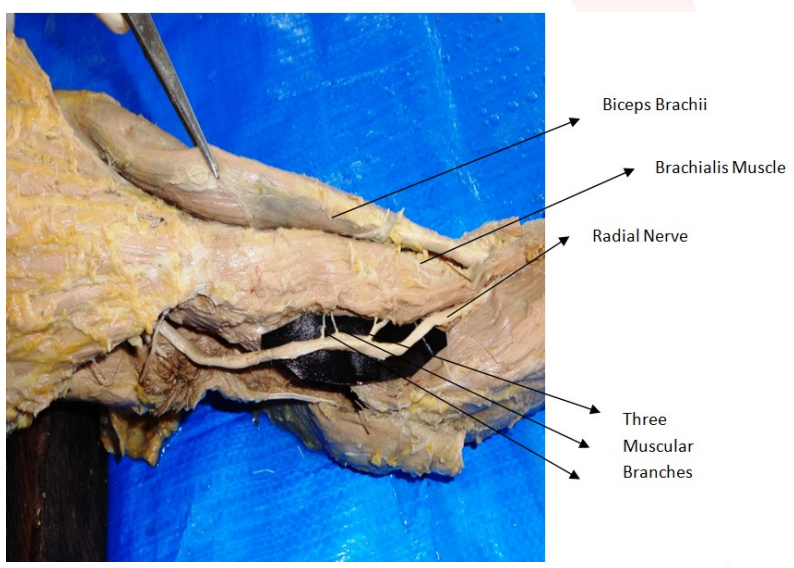

DISCUSSION

The implications of variations in nerve to human brachialis muscles may be important for academic and clinical purposes.

The dual nerve supply of the brachialis (by musculocutaneous and radial) can be explained on the basis of its embryological development. With the elongation of the limb buds, the muscle tissue splits into the flexor and the extensor components which are innervated by corresponding spinal segments. Each ventral ramus gives a ventral and a dorsal branch. Thus, the radial nerve which supplies the extensor musculature is formed by a combination of the dorsal branches, whereas the ulnar and the median nerves which supply the flexor musculature are formed by a combination of the ventral branches. Though the brachialis is a flexor, the radial nerve gives a minor branch (C7) to the brachialis muscle. This is explained by the derivation of the lateral portion of the muscle from the extensor pre-muscle mass. The double nerve supply of the brachialis by the musculocutaneous nerve and the radial nerve has been generally explained to be the result of the fusion of two muscular primordia, the extensor pre-muscular mass and the flexor pre-muscular mass.

The branch of radial nerve which innervated the brachialis muscle is considered to be proprioceptive. The brachialis muscle contains a large number of mechanoreceptors and thus, coupled with its innervation pattern, it plays a key role in the kinaesthetic awareness and the proprioception concerning the elbow [9]. The innervations of a specific muscle is probably regulated by cues produced by the muscle itself. Once the motor fibres have found their target muscles, the sensory fibres grow along the motor axons and innervate the sensory end organs in the limbs [10].

As reported by many workers in various populations, the radial nerve supply to the brachialis muscle may remain absent in a significant proportion of cases. Table 3 indicates the incidence of radial nerve innervations in various populations. Our findings ( $87.09 \%$ cases) are not much different as compared with other workers (Table 3).

Usually a single branch from radial nerve innervates to brachialis muscle, however innervations by two to three branches are not uncommon. Mahakkanukrauh P, Somsarp $\mathrm{V}^{[11]}$ observed only one muscular branch in $100 \%$ specimens. This is in marked contrast to our study (Fig. 2). The variation in the branch number may be due 
Table 3: Comparison of data obtained by previous studies with that of present.

\begin{tabular}{|c|c|c|c|}
\hline Sr. No. & Various Parameters & Prevalence (\%) & Quoting Author \\
\hline 1 & Radial Nerve Branch to Brachialis Muscle. & $\begin{array}{c}81.6 \\
67 \\
72.14 \\
88 \\
70 \\
87.09\end{array}$ & $\begin{array}{c}\text { Mahakkanukrauh P, Somsarp V[11] } \\
\text { Blackburn SC et al[12] } \\
\text { Prakash I et al[13] } \\
\text { Srimathi T, Umapathy Sembian[14] } \\
\text { Shalini Chaudhary, Sarvesh, Rimpi Gupta[15] } \\
\text { Present study }\end{array}$ \\
\hline 2 & $\begin{array}{c}\text { Site of Entry of Radial Nerve Branch To } \\
\text { Brachialis Muscle. }\end{array}$ & $\begin{array}{c}\text { U1/3-0, M1/3-17 L1/3-83 } \\
\text { U1/3-0, M1/3-34.29, L1/3- } \\
65.71 \\
\text { U1/3-0, M1/3-34.29, L1/3- } \\
65.71 \\
\text { U1/3-4, M1/3-24, L1/3-84 } \\
\text { U1/3-19.35, M1/3-43.54, } \\
\text { L1/3-91.93 }\end{array}$ & $\begin{array}{l}\text { Mahakkanukrauh P, Somsarp V [11] } \\
\text { Frazer EA et al[16] } \\
\text { Prakash I et al[13] } \\
\text { Srimathi T, Umapathy Sembian[14] } \\
\text { Present study }\end{array}$ \\
\hline
\end{tabular}

to the differences in the muscle's architecture, the brachialis are essential in the treatment of the number of joints which a muscle crosses, and the variations which are in need for the isolated control of different parts of a common muscle belly.

Almost all the authors (Mahakkanukrauh $\mathrm{P}$, Somsarp V[11], Frazer EA et al.[16], Prakash et al.[13] , Srimathi T, Umapathy Sembian[14]) have indicated that in large proportion of cases the site of entry of the radial nerve branches into the brachialis muscle was in its lower one-third (Table 3)

The length of the muscular branches varied in the first, second and the third branches from the radial nerve. Srimathi T, Umapathy Sembian.[14] in his study the radial nerve into brachialis muscle the average length of these muscular branches is $4.4 \mathrm{~cm}$. In present study, the average length of these muscular branches is $9.17 \mathrm{~mm}$. The results of Bacakoglu A K et al.[17] were similar to our study.

The average distance from the site of emergence of the muscular branches to the lateral epicondyle, as recorded by Many other workers (Srimathi T, Umapathy Sembian.[14], Linell EA.[18] , Guse T R, Ostrum R. F.[19] and Carlan D, Pratt J, Patterson JM, Weiland AJ, Boyer MI, Gelberman RH.[20]). Their measurements were not much different from the measurement obtained by present study $(6.54 \mathrm{cms})$.

It is quite evident that a thorough knowledge of the innervation of the brachialis and the anatomical relationship of the radial nerve to the fractures of the shaft of the humerus (supraepicondylar fracture), for performing surgery in its vicinity and for performing motor nerve blocks[3].

\section{CONCLUSION}

Various data in relation to the radial nerve supply of brachialis muscle were obtained for Gujarat population. In a large proportion of limbs radial nerve was innervating brachialis muscle. Most of these branches were supplying brachialis in its lower $1 / 3^{\text {rd }}$ part. The average distance of this branch was $6.54 \mathrm{~cm}$ from lateral epicondyle.

These data from cadavers of Gujarat region will be of use to anesthetists, orthopedic and general surgeons in treating the supracondylar fractures of humerus, nerve block and surgery in the vicinity of elbow region.

\section{Conflicts of Interests: None}

\section{REFERENCES}

[1]. Datta A.K. Principles of general anatomy, $6^{\text {th }}$ edition. Current books international, Kolkata 96-100.

[2]. Williams et al. Gray's Anatomy, $39^{\text {th }}$ edition. London: Churchill 855.

[3]. Moore KL. Clinically Oriented Anatomy, 5th edition, Philadelphia, London: Lippincott Williams and Wilkins; 2006; 784-801.

[4]. Vishram singh. Textbook of anatomy, reed Elsevier India private limited $2^{\text {nd }}$ edition.2014; 95.

[5]. Datta A.K. Essential of Human Anatomy, (Superior and Inferior Extremities), $4^{\text {th }}$ edition. 2012; 63. 
[6]. Last RJ. Anatomy Regional and Applied, 11th edition. London: English language Book society and Churchill Livingstone. 2006; 60-6.

[7]. Datta A.K. Essential of human anatomy Neuroanatomy, $3^{\text {rd }}$ edition, current books international, Kolkata 269.

[8]. Cunningham's Manual of Practical Anatomy (Upper and Lower Limbs) Volume I, $15^{\text {th }}$ edition 71-2.

[9]. Saddler. Langman's Medical Embryology, 10th edition. Philadelphia: Lippincott Williams and Wilkins. 2000;143-9.

[10]. Dr. A K. Datta Essential of human Embryology, 6th edition. Kolkata books international. 2010:286.

[11]. Mahakkanukrauh P, Somsarp V. Dual innervation of the brachialis muscle, Clinical Anatomy, 2002;15(3):206-9.

[12]. Blackburn S. C., Wood C. P. Evans D. J., Watt D. J. Radial nerve contribution to brachialis in the UK Caucasian population: position is predictable based on surface landmarks, ClinAnat. 2007;20(1):64-7.

[13]. Prakash I, Kumari J, Singh N, Deep RG, Akhtar T, Sridevi NS, et al. A cadaveric study in the Indian population of the brachialis muscle innervations by the radial nerve. Romanian Journal of Morphology and Embryology. 2009; 50(1):111-4.

[14]. Srimathi T, Umapathy Sembian. A Study on the Radial Nerve Supply to the Human Brachialis Muscle and Its Clinical Correlation. Journal of Clinical and Diagnostic Research. 2011 October;5(5): 986-9.
[15]. Shalini Chaudhary, Sarvesh, Rimpi Gupta. Dual Innervation of Human Brachialis Muscle. Sch. Acad. J. Biosci. 2015; 3(2A):124-7.

[16]. Frazer E. A., Hobson M., Mcdonald S. W., The distribution of the radial and musculocutaneous nerves in the brachialis muscle. ClinAnat. 2007; 20(7): 785-9.

[17]. Bacakoglu AK, Kira A, Muratlil K, Ekin A, Ergur I. Medial transposition of the radial nerve for anterolateral plate fixation of the humerus: cadaveric study. Anatomical Science International. 2007; 82:116-20

[18]. Linell EA. The distribution of nerves in the upper limb, with reference to the Variabilities and their clinical significance. J Anat.1921; 55:79-112.

[19]. Guse T. R., Ostrum R. F. The surgical anatomy of the radial nerve around the humerus. ClinOrthopRelat Res. 1995; 320:149-53.

[20]. Carlan D., Pratt J., Patterson J. M., Weiland A. J., Boyer M. I., Gelberman R. H. The radial nerve in the brachium: an anatomic study in human cadavers. J Hand Surg [Am]. 2007;32(8):1177-82.

How to cite this article:

Natwar Lal Gaur, Jagdish S. Soni, Samta Gaur. THE INNERVATION OF BRACHIALIS MUSCLE BY RADIAL NERVE IN GUJARAT REGION - A HUMAN CADAVERIC STUDY. Int J Anat Res 2020;8(1.2):7328-7332. DOI: $10.16965 /$ ijar.2019.369 